\section{Royal Society Elections}

AT the meeting of the Royal Society on June 25 it is proposed to elect Sir Thomas Middleton as a fellow under Statute 12, which provides for the election of persons who "either have rendered conspicuous service in the cause of science, or are such that their election would be of signal benefit to the Society". The following foreign members will also le elected: Prof. Sigmund Freud, Vienna; Prof. Ludwig Jost, Heidelberg ; Dr. F. A. Vening Meinesz, Utrecht; and Prof. Hermann Weyl, Princeton.

\section{Prof. H. E. Armstrong: Doyen of the Royal Society}

WE are glad to have the opportunity of printing the following letter received by Prof. H. E. Armstrong from the president of the Royal Society :

"Dear Professor Armstrong,

"In the name of the Officers and Council of the Royal Society, and in my own, I send you hearty congratulations on your completion of sixty years in the Society's Fellowship and wish you continued health and activity in the years to come.

"Yours sincerely, "W. H. Bragg, President R.S."

To the Royal Society's greetings we add our own to one who has long been a stimulating-and often provocative - contributor to our columns, and by his teaching and sympathetic guidance, has inspired several generations of students of various branches of chemistry. It may be recalled that on the occasion of Prof. Armstrong's golden wedding, a number of friends and old students presented to him a striking portrait by Mr. T. C. Dugdale, a photograph of which was reproduced in NATURE of September 10, 1927 (p. 379). Prof. Armstrong is the senior fellow of the Royal Society, having been elected in 1876 ; next in years of service come Sir James Crichton-Browne, elected 1883, and Sir J. J. Thomson, elected 1884. His fellowship of the Chemical Society, of which he was president so long ago as 1893-95, goes back even further, namely, to 1870. Scientific workers everywhere will wish to congratulate Prof. Armstrong on the accomplishment of so many years of fruitful activity.

\section{Sir Robert Mond and Industrial Chemistry}

SIR RoBERT MOND has been elected president of the Société de Chimie Industrielle of France. Sir Robert, who was recently awarded the Messel Medal of the Society of Chemical Industry in Great Britain, is to deliver his medal address, on "Works as I have seen them grow", during the annual meeting of the Society in Liverpool on July 6-10. He has been, and still is, associated with a number of important firms in the chemical industry. A great deal of his original work has been in connexion with electro-chemical processes and industrial chemistry, and he was at one time associated in his work with Lord Kelvin. The Messel Medal of the Society of Chemical Industry is awarded every alternate year to a scientific worker who has attained eminence in applied chemistry.

\section{Nova Lacertæ 1936}

A Nova of the third magnitude was discovered on the night of June 18-19 by Dr. Nielsen, of Aarhus, Denmark, who happened at the time to be one of a party of astronomers on board the $P$. and $O$. steamer Strathaird which was going to view the total eclipse of June 19 from a station off the coast of Greece. The nova was observed through cloud in England on the night of June 19-20; estimates of the magnitude were difficult to make on account of the cloud, but the star was probably not brighter than the second magnitude. The spectrum was photographed at Greenwich and found to be of $F$ type with strong absorption lines and weak emission bands, recalling the spectrum of Nova Herculis 1934 on December 23, 1934. Unfortunately, the weather has not been favourable for observations in and about London as we go to press, but according to Dr. Steavenson the nova is already decreasing in brightness. An accurate position was obtained at the Royal Observatory, Greenwich, with Airy's transit circle on the morning of June 21 by Mr. Symms, who estimated a magnitude of $3.0 \mathrm{~m}$. The apparent position referred to the equinox of date (June 21,1936 ) is R.A. $22^{\mathrm{h}} 13^{\mathrm{m}} 22 \cdot 5_{\mathrm{s}}$, Dec. $+55^{\circ} 17^{\prime} 5 \mathrm{I}^{\prime \prime}$. The nova may still be a nakedeye object for a few nights to come : since it is so far north, it is visible throughout these short nights, although the meridian transit takes place in the early morning. The nova should be identified readily as follows. Half-way between the constellation of Cassiopeia and the conspicuous figure of Cygnus is an equilateral triangle of stars formed by $\delta$ Cephei, $\zeta$ Cephei and the nova; half-way between the nova (the southernmost of the three) and $\zeta$ Cephei is a centre star, $\varepsilon$ Cephei.

\section{Louis Pasteur Film}

The Louis Pasteur film, of which a gala first night exhibition took place at the New Gallery Kinema, Regent Street, London, on Monday, June 22, in aid of St. Peter's Hospital, Covent Garden, was in more than one sense a remarkable event. The title role was taken by Mr. Paul Muni, who had obviously made a careful study of the great French savant in all his strength and weakness. Not only were his passionate ardour in research, dauntless courage in facing opposition and sympathy for human suffering admirably portrayed, but also his abruptness, outbursts of temper, and fits of despondency. It is, therefore, all the more regrettable that the film should contain many historical errors. We are shown, for example, Napoleon III, who in actual fact always took a warm interest in Pasteur's investigations, forbidding him to continue his researches on anthrax and to recant what he had already written on the subject, whereas his work on anthrax was not commenced until after the Emperor's death. Lister is represented as making a special journey to France to witness the results of Pasteur's inoculation of sheep against anthrax in 1881, whereas these two great men did not meet until 1892, when Lister represented the Royal Society at the ceremony held at the Sorbonne in honour of Pasteur's seventieth 